\title{
Les Habilitats Socials, clau per a la millora de la convivència a les aules de l'E.S.O Una proposta innovadora
}

Tamara Zafón Celades tzc_villaherpuertomin1990@hotmail.com

Amanda Ballester Serrano amandaballesterserrano@hotmail.com 


\section{Resum}

Les Habilitats Socials cobren especial rellevància en diferents àmbits per l'existència de relacions entre la competència social en els joves i el posterior funcionament social, acadèmic i psicològic. Bandura (1976) remarca en la seva Teoria de I'Aprenentatge Social que les habilitats socials s'adquireixen mitjançant reforçament positiu i directe de les habilitats, mitjançant aprenentatge vicari u observacional, mitjançant retroalimentació interpersonal i mitjançant el desenvolupament d'expectatives cognitives respecte a les situacions interpersonals.

Veient la importància d'aquestes amb els joves en l'àmbit escolar, l'objectiu de la nostra comunicació és mostrar l'anàlisi realitzada a professors de I'IES El Caminàs de Castelló, a través d'un qüestonari elaborat per estudiants de Psicopedagogia de la Universitat Jaume I que recull informació sobre les HHSS a l'aula i les debilitats i fortaleses que, en la seva opinió, existeixen en aquest centre. L'anàlisi descriptiva es va dur a terme a través del sps.18 els resultats del qual ens indiquen que existeixen necessitats en relació a les HHSS de l'alumnat i els recursos perquè el professorat les pugui treballar. Així, proposem un projecte d'intervenció amb l'objectiu de formar a l'alumnat de primer cicle de la E.S.O en les HHSS per a la millora, tant a nivell personal com a comunitari i aconseguir posar en pràctica els coneixements adquirits en tots els àmbits de la vida.

Autoconeixement, comunicació i resolució de conflictes són tres grans blocs que formen el projecte. S'aplica al llarg de tot un curs lectiu: primer trimestre per a la formació docent a l'àrea de les HHSS, segon trimestre destinat al treball dels tutors amb el seu alumnat en l'hora de tutoria mitjançant la realització d'activitats cooperatives i tècniques d'entrenament i tercer trimestre per avaluar el programa per part de tots els agents implicats.

Paraules clau: Anàlisi, qüestionari, habilitats socials, necessitats, alumnat, secundària, professorat, convivència, innovació i prevenció.

\section{Introducció}

Actualment les Habilitats Socials estan cobrant especial rellevància en diferents àmbits per l'existència de relacions sòlides entre la competència social en els joves $\mathrm{i}$ el posterior funcionament social, acadèmic i psicològic. A més, la nostra societat demanda un determinat tipus d'home i de dona en el futur, capaç de prendre decisions, treballar en equip, resoldre conflictes, adequar-se als canvis, controlar les seves emocions, saber comunicar les seves necessitats... 
Dins d'aquest context, el concepte d'Habilitats Socials fa referència al conjunt de comportaments eficaços per a les relacions interpersonals. Bandura (1976) remarca en la seva Teoria de l'Aprenentatge Social que les HHSS s'adquireixen mitjançant reforçament positiu i directe de les habilitats, mitjançant aprenentatge vicari u observacional, mitjançant retroalimentació interpersonal i mitjançant el desenvolupament d'expectatives cognitives respecte a les situacions interpersonals.

L'escola com a part de la societat, no pot oblidar la importància de treballar les HHSS en el procés d'educació dels infants i adolescents. Com afirmen Trianes i Muñoz (1997), necessitem programes dissenyats des d'una perspectiva educativa per ser desenvolupats a l'aula pels docents, impregnant les metodologies del professor, introduint nous objectius en l'aprenentatge de les matèries escolars i ajustats al context escolar. Aquí és on les HHSS poden jugar un paper important, doncs milloren la convivència així com prevenen i redueixen previsibles conflictes.

Donada la importància que té el desenvolupar en els joves la competència social junt a les diverses assignatures curriculars, sorgeix la curiositat d'investigar en un institut de secundària de la província de Castelló les mancances que presenta l'alumnat quant a la formació en l'àrea social i les mancances del professorat quant a materials i projectes destinats a desenvolupar aquest tipus d'estratègies. Tot i axó, el centre en el que ens hem basat per a portar a terme aquesta investigació és un Institut d'Educació Secundaria Obligatòria situat a la perifèria de la ciutat. Es tracta de l'IES El Caminàs que té gran varietat d'oferta educativa, quant a cicles formatius fa referència, a més a més de tindre adscrites les escoles dels barris pròxims com són el col·legi Blasco lbañez y el Fadrell. Per tant, la situació socioeconòmica i cultural dels alumnes que en aquest centre trobem és molt variada, fent de I'IES El Caminàs una institució heterogènia, plural i oberta.

Fen referència específicament a la mostra de la població amb la que en aquest cas hem treballat, es tracta dels docents i alumnes del primer curs de I'ESO del centre nomenat anteriorment, ja que trobem que en èpoques de transició, com es el canvi del col·legi de primària al centre de secundària, és quan els xiquets deuen desenvolupar les habilitats necessàries per poder aprendre a adaptar-se a la vida. Com sabem per investigacions realitzades anteriorment, el comportament interpersonal d'un xiquet juga un paper vital en l'adquisició de reforçaments socials, culturals i econòmics, per la qual cosa els nens que tenen mancances en els apropiats comportaments socials, experimenten aillament social, rebuig $i$, en general, menys felicitat.

Per tot allò, creiem que la formació docent continuada per tal de portar a terme programes que treballen competències adequades per generar un positiu desenvolupament en la vida o ser capaços d'ensenyar estratègies 
socials i educar en habilitats d'aquest tipus és molt important. Aquesta investigació, tracta d'estudiar la situació actual i la realitat més pròxima d'un centre, per tal de poder fer propostes de millora i afavorir el treball d'aquells que es troben cada dia amb nous reptes educatius i d'aprenentatge, docents i alumnes. Les propostes innovadores en les aules, afavoriran tant l'aprenentatge significatiu per als joves, com la qualitat de vida de tots els que ens trobem contínuament interactuant socialment. Es tracta de molts aspectes que estan interrelacionats i que si es tenen en compte i es treballen poden fer a la llarga una societat i un món millor.

\section{Objectius}

\section{General}

D'aquesta manera, per a posteriorment poder fer propostes innovadores que treballen les Habilitats Socials en els primers cursos de la E.S.O, l'objectiu principal d'aquesta investigació és comprovar si aquells docents als que se'ls administra el qüestionari de detecció d'Habilitats Socials, observen en els seus alumnes una mancança d'aquest tipus d'actituds necessàries per a la vida (comunicació, empatia, autoconcepte, resolució de conflictes, presa de decisions, etc) així com afirmen o no l'existència d'activitats o formació que possibilita el treball d'aquestes en l'aula tant a nivell individual com grupal.

\section{Específics}

Per altra banda, com a objectius específics o associats a tot aquest procés d'investigació-acció que hem portat a terme, plantegem els següents:

- Analitzar una realitat educativa immediata.

- Analitzar l'opinió docent sobre el nivell d'Habilitats Socials dels seus alumnes.

- Fomentar la formació docent.

- Conèixer les possibilitats de treballar a l'aula les Habilitats Socials.

- Conèixer les mancances i fortaleses del centre per a tindre un punt de referència coherent amb la realitat per a la posterior proposta d'intervenció innovadora.

- Millorar el clima del centre.

- Millorar l'autoconeixement de tots els membres de la comunitat educativa. 
Després de dur a terme una anàlisi exhaustiva del Projecte Educatiu del Centre en el qual es basa la nostra investigació, procedirem a la detecció de les necessitats educatives del mateix. Per partir d'una base fonamentada en la situació real de la institució, vam escollir una mostra de la població total amb la qual treballar sobre el tema del nostre interès. Per tant, vam portar a terme un quasi-experiment realitzat a través d'una enquesta transversal que ens ha permès recollir informació mitjançant un qüestionari. D'aquesta manera, estudiants de l'últim curs de la Llicenciatura en Psicopedagogia varen crear un qüestionari com a instrument centrat en la temàtica sobre la qual volíem investigar, les Habilitats Socials a l'aula. Aquest, estava format per una sèrie d'ítems d'identificació inicials, vint-i-dos ítems de resposta tancada i tres qüestions obertes d'observacions. Per als ítems de resposta tancada, vam utilitzar una escala de categories basada en la escala tipus Likert (amb cinc possibles opcions de resposta): $1=$ mai, 2 = gairebé mai, $3=$ normalment, $4=$ gairebé sempre i $5=$ sempre. Aquest pretenia reflectir les valoracions dels docents segons el nivell d'Habilitats Socials observat en els seus alumnes, així com la importància que aquestos trobaven en formar-se per a la millora de les seues habilitats en aquesta àrea social com a professionals educatius. Els ítems que formen part d'aquest qüestionari són:

Ítems d'identificació:

- Gènere.

- Nivell docent.

- Anys d'experiència.

- Edat.

Ítems de resposta tancada:

1. Saluden pels matins amb educació al arribar a l'aula.

2. Són capaços de mantindre una escolta activa al llarg de tota la classe.

3. Són capaços de portar a terme un debat respectant el torn d'intervenció.

4. Respecten les opinions de la resta a pesar de ser contraries a les seves.

5. Reconeixen els assoliments dels seus companys sense mostrar desgrat per haver sigut superats.

6. Ajuden voluntàriament als seus companys en activitats de classe.

7. Són capaços de resoldre conflictes mitjançant el diàleg.

8. Utilitzen l'agressivitat com mitjan de resolució de conflictes.

9. Participen en classe contínuament sense que suposi massa esforç per a ells. 
10. Pregunten sense problema (vergonya a les reaccions de la resta) davant de qualsevol tipus de dubte.

11. Són capaços d'agrair a la resta els favors que se'ls ofereixen.

12. Són capaços de demanar ajuda quan tenen alguna dificultat.

13. Intenten reconèixer les emocions que experimenten en les diferents situacions que es donen a l'aula.

14. Permeten que els demés conegueu el que senten.

15. Intenten comprendre el que senten els demés.

16. Comparteixen amb la resta de companys els materials de l'aula.

17. Es mantenen al marge de situacions que els poden generar problemes.

18. Es responsabilitzen dels seus errors quan són donats.

19. Prenen les seues pròpies decisions malgrat el que la resta pense.

20. Consideren les possibilitats abans de prendre qualsevol tipus de decisions.

21. Són realistes a l'hora de prendre consciència de les seves pròpies possibilitats front a les activitats.

22. Actuen en grup per por a ser exclosos.

Qüestions obertes d'observacions:

- ¿Quines mancances creus que presenta el centre quant al treball de les Habilitats Socials?

- ¿Quins punts forts creus que presenta el centre quant al treball de les Habilitats Socials?

- ¿Estàs interessat amb rebre informació sobre aspectes relacionats en el presentat al qüestionari?

La mostra a la que es va administrar aquest qüestionari van ser 17 docents de l' IES EI Caminàs de Castelló que treballaven en alguna matèria amb els alumnes de primer curs de I' ESO. Es va tractar d'un mostreig no probabilístic perquè la mostra no va ser assolida aleatòriament i, per tant, els resultats no poden ser generalitzables per a tota la població. A més a més, es tracta d'un mostreig no probabilístic fortuït o accidental perquè el qüestionari va ser contestat pels docents del centre que van voler fer-ho de forma totalment voluntària.

El procediment que vam seguir per a portar a terme aquest treball va ser específicament el següent. En primer lloc, vam realitzar una cerca dels diferents centres d'Educació Secundaria Obligatòria que teníem al nostre abast per demanar el seu interès i la seua collaboració en un treball d'aquest tipus. Desprès d'intentar aconseguir almenys un que colllaborara, vam decidir centrar-nos en el IES El Caminàs que era el que més curiositat va sentir pel tema de les Habilitats Socials i la nostra actitud investigadora front a la millora del funcionament del sistema educatiu. Per tant, ja teníem un centre que ens permetia portar a terme un projecte innovador en base a les necessitats detectades en l'anàlisi de 
la seua realitat. Durant un temps, es van realitzar diverses observacions durant l'estona del pati i es va analitzar el Projecte Educatiu del Centre per tal de conèixer la realitat amb la qual anàvem a tractar. Desprès va ser necessari un temps de treball fora del centre per part de l'equip d'investigadores que treballàvem juntes per la creació del qüestionari de detecció de mancances en l'alumnat quant a Habilitats Socials observades pels docents. Seguidament, gràcies a l'equip directiu del centre ens van ficar al nostre abast el llistat de docents que impartien classe a primer d'ESO, per poder demanar la seua col·laboració voluntària i vam passar a la recollida de dades. Els vam donar un temps màxim d'entrega del qüestionari al cap d'estudis del centre i una volta complida la data, vam replegar tota la informació per analitzar-la. Contàvem amb una mostra de 17 docents tot i que érem conscients que hi havien de 5 a 10 subjectes perduts que no havien entregat el qüestionari, motiu del qual desconeixem. Finalment, vam portar a terme l'anàlisi de les opinions replegades en el qüestionari mitjançant el programa estadístic SPSS.18. que ens donaria els percentatges, gràfiques i dades més rellevants per poder obtindre conclusions.

El temps durant el qual es va portar a terme aquesta investigació va ser aproximadament d'uns 5-6 mesos durant els quals vam analitzar el Projecte Educatiu del Centre, vam realitzar diverses observacions tant en l'aula com en els horaris de pati i temps lliure, vam realitzar el qüestionari utilitzat per a la recollida d'informació i vam analitzar totes les dades recollides. També, es va realitzar la proposta d'intervenció per a la millora de la realitat analitzada i es va ficar en mans del centre per a la seua possibilitat de posada en pràctica el projecte innovador que va ser creat en base a les mancances detectades.

Hem de tenir en compte que, tot i que aquesta investigació està basada en les opinions dels docents davant les Habilitats Socials que tenen els seus alumnes, donades les mancances detectades per poder treballar en un futur per a la millora d'aquestes competències, els docents deuen aprendre a detectar el nivell d'Habilitats Socials en els seus alumnes per poder crear una intervenció adequada i, finalment, saber analitzar o valorar com ha evolucionat la seua classe a nivell social gràcies a tot aquest procés. Per tant, en aquest cas es tracta d'una part molt centralitzada de la investigació, però que té una sèrie de beneficiaris a llarg termini com són els mateixos alumnes i la millora de la convivència tant al centre educatiu, com amb la família i en la societat en general si tot el procés d'investigació-acció es porta a terme de forma continuada.

\section{Resultats}

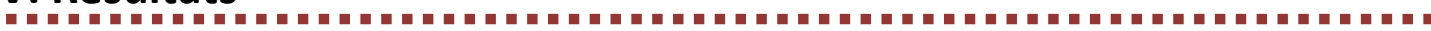

Després de l'aplicació del qüestionari de recollida d'informació, "Qüestionari de detecció de mancances en les Habilitats Socials", i haver 
realitzat l'avaluació dels resultats obtinguts, creiem convenient destacar aquells ítems que reflecteixen una clara mancança d'Habilitats Socials, per part de l'alumnat a l'aula segons el punt de vista dels docents, i que justifiquen el nostre projecte d'innovació que amb aquesta proposta plantejarem. Per a aquest pas, utilitzem el programa estadístic SPSS.18. que ens va facilitar l'obtenció de gràfiques i figures, com seguidament veurem.

La mitjana d'edat dels docents que han format part d'aquest grup d'enquestats és de 38 anys amb una mitjana d'experiència de 13 anys, dels quals un $35,3 \%$ són homes i un 64,7 \% són dones.

Dels 22 ítems dels quals consta el qüestionari, l'interval de resposta se situa entre "Normalment" i "Mai". Tot i que realment les respostes "Normalment" són majoritàries, és primordial per a la realització del nostre treball tenir en compte l'existència $d$ ' ítems que han estat valorats molt negativament amb les respostes "Mai" i "Gairebé mai" les quals rebran una anàlisi més exhaustiva a continuació perquè proporcionaran informació clau per a la fonamentació d'aquest treball. Per aquest motiu, seguidament passem a destacar aquells ítems que reflecteixen la necessitat de plantejar recursos per al treball de les Habilitats Socials en aquest centre.

Com s'observa en la Gràfica 1, a continuació, enfront de l'ítem "Són capaços de mantenir una escolta activa al llarg de tota la classe", la resposta majoritària per part del professorat ha estat "Gairebé mai", deixant un petit rang de respostes en "Normalment" i descartant la resta d'alternatives possibles.

Gràfica 1. Qüestionari de detecció de mancances en les Habilitats Socials item 2

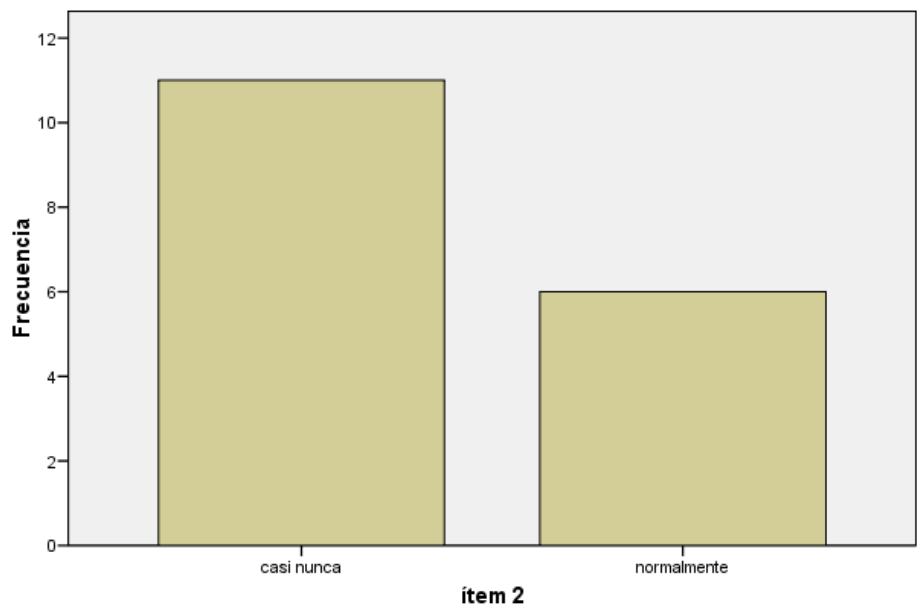

Seguidament, en la Gràfica 2, observant l'ítem "Són capaços de dur a terme un debat respectant el torn d'intervenció" veiem que gairebé mai 
es duu a terme aquest tipus de conductes que mostren gran mancança de pautes de comportament perquè es desenvolupen les classes de forma organitzada.

Gráfica 2. Qüestionari de detecció de mancances en les Habilitats Socials item 3

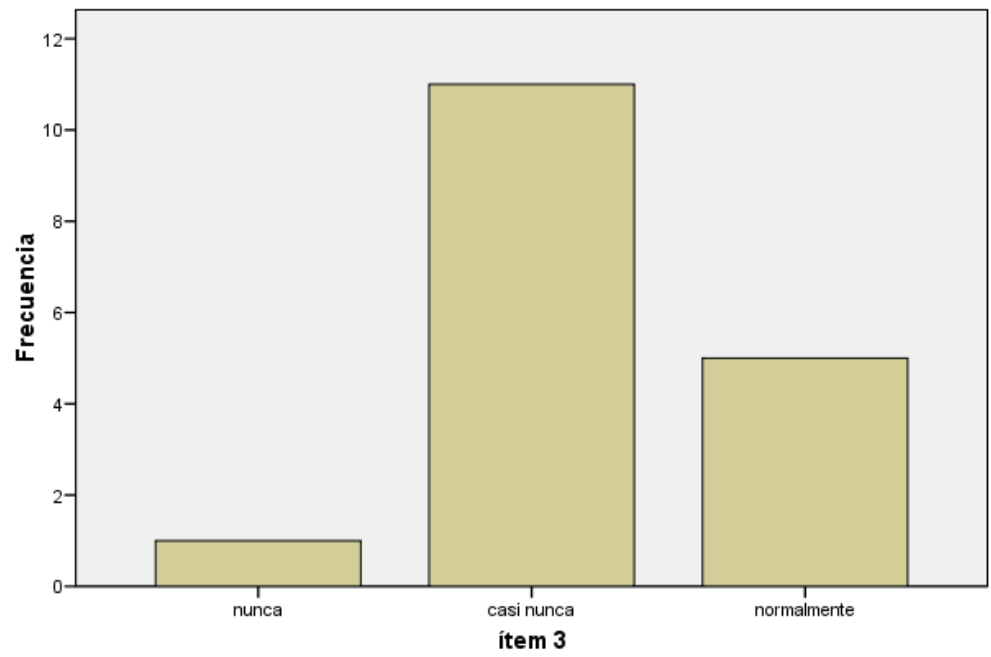

En el següent ítem, Gràfica 3, "Intenta reconèixer les emocions que experimenta en les diferents situacions que es donen a l'aula", veiem una mancança important en aspectes que fan referència a la intel-ligència emocional, per la qual cosa la nostra labor serà desenvolupar activitats que treballin les emocions de l'alumnat.

Gràfica 3. Qüestionari de detecció de mancances en les Habilitats Socials

item 13

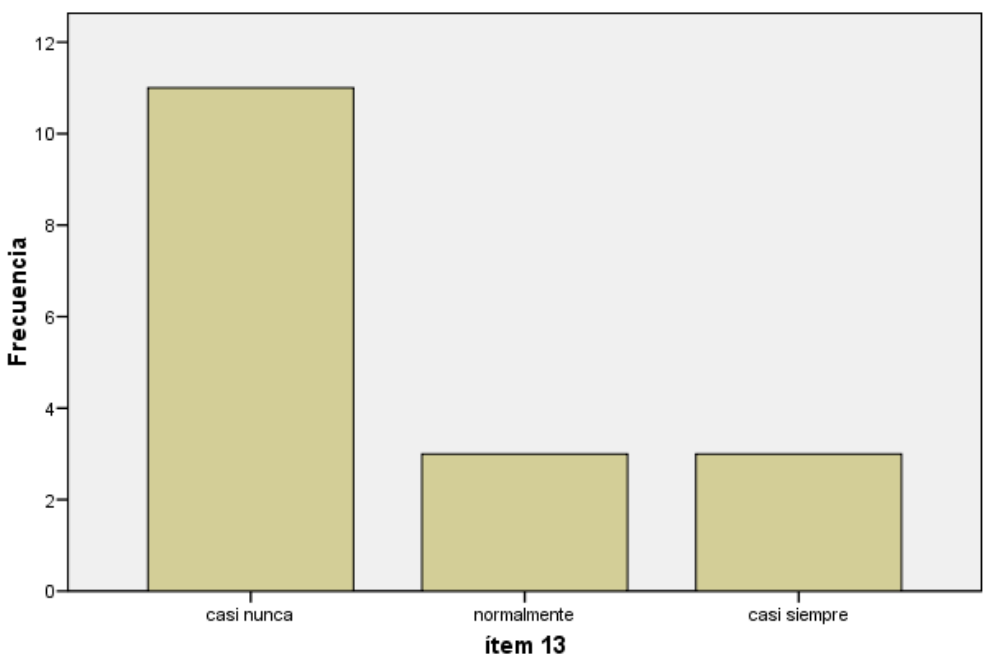

A continuació, l'ítem "Prenen les seves pròpies decisions malgrat el que pensi la resta", corresponent a la Gràfica 4, mostra una clara necessitat de desenvolupar en l'alumnat la importància de la presa de decisions enfront 
de l'opinió de la resta per a les diferents situacions a les quals hagin de fer front.

Gràfica 4. Qüestionari de detecció de mancances en les Habilitats Socials

ítem 19
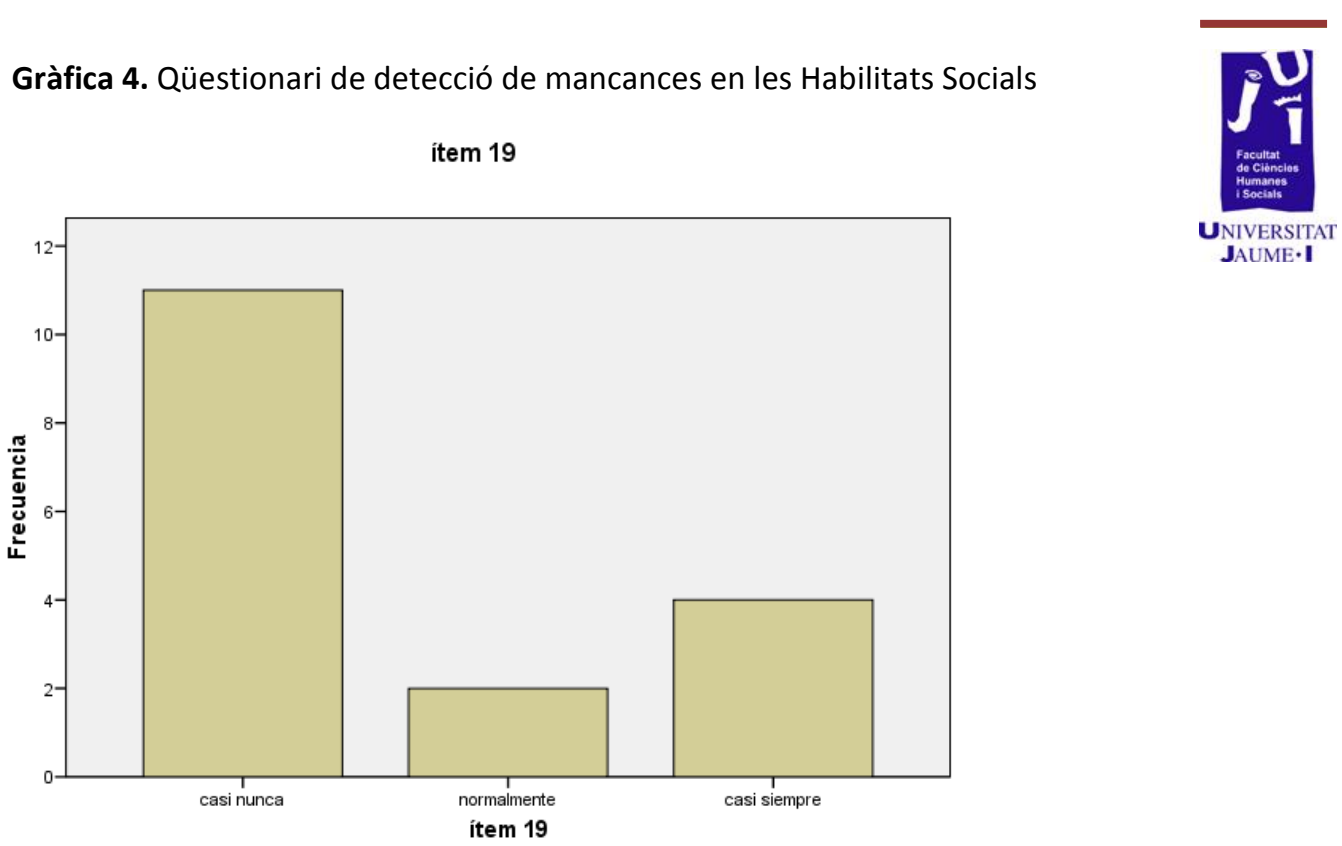

Seguidament, es presenta la Taula 1 que mostra el resum de les respostes per part del propi psofessorat quant a les fortaleses i debilitats que creuen tenir al seu centre:

\begin{tabular}{|c|c|}
\hline \multicolumn{2}{|c|}{ TAULA 1} \\
\hline FORTALESES & DEBILITATS \\
\hline $\begin{array}{l}\text { - } \quad \text { Els docents escolten a l'alumnat. } \\
\text { - } \quad \text { Grups estables que es mantenen al } \\
\text { Ilarg de l'etapa. } \\
\text { - } \quad \text { Bona atenció a l'alumnat amb N.E.E o } \\
\text { amb problemes de comportament. } \\
\text { - } \quad \text { Contacte amb les famílies. } \\
\text { - } \quad \text { Educació i respecte per part de cert } \\
\text { - } \quad \text { Pector d'alumnat } \\
\text { - } \quad \text { professonalitat i carisma d'alguns } \\
\text { - } \quad \text { Bs pronibilitat dels docents per tractar } \\
\text { Bona predisposició de l'alumnat a } \\
\text { treballar. } \\
\text { Bona participació de l'alumnat }\end{array}$ & $\begin{array}{l}\text { - L'alumnat no està preparat per a } \\
\text { realitzar debats ja que no saben escoltar- } \\
\text { se. } \\
\text { - No es fomenten temes generals de } \\
\text { discussió a nivell de centre. } \\
\text { - Pocs programes d'aula que treballin la } \\
\text { convivència o la mediació. } \\
\text { - Poc enfocament de l'acció tutorial. } \\
\text { - Falta d'acord entre docents quant a les } \\
\text { normes de classe. } \\
\text { - Falta d'atenció als problemes en } \\
\text { alumnat "normal". } \\
\text { - L'alumnat no s'enfronta conjuntament } \\
\text { als problemes que puguin sorgir a l'aula. } \\
\text { - Alta ràtio d'alumnes a l'aula. } \\
\text { - Sobretot en } 1 r \text { ESO, sorgeix la necessitat } \\
\text { de treballar les Habilitats Socials. } \\
\text { - Falta treball en equip per part dels } \\
\text { docents. }\end{array}$ \\
\hline
\end{tabular}

Com es pot observar, en general, es va detectar una mancança d'Habilitats Socials per part dels alumnes, segons les conductes 
observades pel professorat a l'aula. Per aquest motiu varem desenvolupar un projecte d'innovació de caràcter preventiu destinat a posar en pràctica una sèrie d'activitats pràctiques i dinàmiques per fomentar les relacions interpersonals a les aules del primer curs de I' ESO i, en definitiva, millorar la convivència en el centre. La idea principal per crear el projecte era basar-nos en aquelles mancances específiques que mostrava l'alumnat en l'aula (incapacitat de dur a terme un debat, poc treball en equip, falta de reflexió per a la presa de decisions...) i treballarles aprofitant al màxim aquells punts forts del que disponia l'institut i els seus professors (disponibilitat i escolta cap a l'alumnat, carismàtics, bon tracte amb les famílies, tracte fluïd amb la directiva...).

Cal enfocar aquest programa dins de la intervenció tutorial, és a dir, el programa està pensat per impartir-se durant tot un trimestre lectiu en les hores de tutoria i es posarà en pràctica durant el segon trimestre, destinant el primer trimestre a la detecció de les mancances de les HHSS de l'alumnat i el tercer a l'avaluació de tot el procés realitzat junt amb l'aplicació del projecte.

Quant al responsable de l'aplicació del projecte serà el tutor/a de cada grup de $1 r$ d'ESO qui posi en pràctica les activitats amb els seus alumnes, ja que anteriorment s'haurà format sobre la temàtica i haurà adquirit tècniques i mètodes d'entrenament en les Habilitats Socials: dinàmiques de grup, jocs de rols, grups cooperatius... No obstant això, per al desenvolupament $\mathrm{i}$ assoliment de l'objectiu del programa serà necessària la col·laboració de tots els col-lectius implicats, és a dir, de les famílies, de la resta de professorat i de la pròpia institució educativa.

\section{Discussió i conclusions}

Per tant, atenent a les necessitats detectades en l'alumnat i la importància de fomentar en els joves una bona competència social, doncs com bé s'ha esmentat en apartats anteriors es deu de promoure el desenvolupament integral de les persones potenciant tot tipus de capacitats i no sols les cognitives o intel-lectuals, creem necessari donar resposta a aquestos alumnes a partir del nostre projecte amb el qual es treballen les Habilitats Socials.

A més, perquè aquesta millora a nivell de centre es doni, cal dir que no solament hem volgut tractar la necessitat de treballar les Habilitats Socials a nivell d'aula. Volem destacar també la proposta futura que hem fet al centre d'incorporar l'aula de mediació perquè tots els nivells la utilitzen quan els siga necessari. Serà el mateix alumnat el mediador del conflicte amb la finalitat d'afavorir un clima de respecte mutu, de comunicació i cooperació que permeti adquirir hàbits de convivència, tolerància i d'aprenentatge. Els mediadors no seran especialistes a donar solucions, ni diran el que cal fer, sinó que intentaran ajudar al fet que les 
parts en conflicte trobin per sí mateixes les solucions que més els convinguin.

Finalment, perquè la posada en pràctica d'un programa innovador d'aquest tipus sigui eficaç, tant el treball a nivell d'aula com a nivell de centre $\mathrm{i}$ fins $\mathrm{i}$ tot personal, portarà un seguiment que ens permetrà avaluar contínuament si els objectius proposats van sent aconseguits. Per això es realitzaran reunions periòdiques amb els professors implicats i els alumnes representants de cada aula permetent a cada agent aportar les seves opinions i experiències al voltant de l'aplicació del projecte.

Creem amb la hipòtesi que amb l'aplicació del projecte d'innovació el primer curs de I'ESO de I'IES el Caminàs millorarà la convivència a les aules i això es veurà reflectit també en la convivència del centre en general.

Tenim aquesta convicció perquè el projecte ha sigut dissenyat i elaborat de manera individualitzada per a aquest centre, realitzant una anàlisi de la realitat basada en les opinions dels docents que imparteixen classes en el centre dia a dia i en les observacions de l'alumnat. Hem creat el projecte adaptat a les necessitats detectades i a les fortaleses que té el centre per a poder abordar-les sense cap impediment i que resulte exitós per a tota la comunitat educativa.

Creiem que tot el que passa a l'aula és un reflexe del comportament o les situacions que d'adults s'experimentaran en la vida social i és important aprendre a conviure, actuar, comportar-se, prendre decisions, respectarse... Pel que seria interessant que totes les institucions educatives tingueren aquests tipus de treballs en compte e intentaren millorar la seva pròpia realitat portant a terme un autoanàlisi que els ajudarà a evolucionar positivament. D'aquesta manera, milloraria la convivència en general i la qualitat de vida de les persones que interactuem en societat.

\section{Bibliografia}

BALleSTER, R. (2002): Habilitats Socials: avaluació i tractament, Madrid, Síntesis.

BANDURA, A. y R. WALters (1974): Aprenentatge social i desenvolupament de la personalitat, Madrid, Alianza.

BERG, B. (2012): El joc de les habilitats socials, Madrid, TEA.

Caballo, V. (1987): Teoria, avaluació i entrenament de les habilitats socials, València, Promolibro.

LUCA, C. I ALTRES (2001): Programa d'habilitats socials en l'ensenyança secundària obligatòria: ¿com puc afavorir les habilitats socials dels meus alumnes? Archidona, Aljibe. 
Pozo, I. (1998): Aprenents i Mestres: la nova cultura de l'aprenentatge, Madrid, Alianza.

RocA, E. (2007): Com millorar les teves habilitats socials: programa d'assertivitat, autoestima i intel/ligència emocional, València, ACDE.

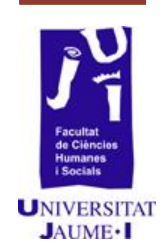


